\title{
The Simulation Analysis of Springback during High-pressure Water Jet Forming for Small Curvature workpiece
}

\author{
Lingyun Zhang ${ }^{1,}$, Z Zhiqiang $\mathrm{Li}^{1, b^{*}}$, Anliang Wang ${ }^{2, \mathrm{c}}$ \\ ${ }^{1}$ Key Laboratory of Fundamental Science for National Defense of Aeronautical Digital Manufacturing \\ Process, Shenyang Aerospace University, No.37 Daoyi South Avenue, Shenbei New Area, \\ Shenyang, China 110136 \\ ${ }^{2}$ Harbin Aircraft Industry (Group) Co. LTD, No.15 Youxie Street, Pingfang District, Harbin, China \\ 150066 \\ azhangly79@163.com, b13390103238@163.com , cwanganliang1961@sina.com
}

Keywords: small curvature workpiece; water jet forming; springback; analysis

Abstract. Most of the aircraft skin parts are with small curvature and the most difficult problem is the controlling of springback. In this paper, the comparison for springback between high-pressure water jet forming and stamp forming is presented by using software ABAQUS. The springback of the high-pressure water jet forming is smaller than stamp forming. It is concluded by using software ABAQUS that between the springback during high-pressure water jet forming and interlayer distance is linear, and as the feed rate increases before the feed speed reaches $750 \mathrm{~mm} / \mathrm{min}$, then can't change basically, which have important reference and practical value to improve the springback of during high-pressure water jet forming for small curvature workpiece.

\section{Introduction}

There are over $30 \%$ small curvature workpiece occupying the whole aircraft sheet metal parts. Small curvature workpiece generally use the stretch forming or stamp forming, all parts need special mold, which isn't suitable for flexible machine. Therefore, it is the direction of the development and research that look for new forming method to adapt to the flexibility and small batch. High-pressure water jet forming technology is a kind of flexible forming technology, combined with water jet technology and incremental forming technology. It has a high forming limit and no heat effect in the process of forming, and belongs to the green machining. In recent years, high-pressure water jet forming has caused the attention and research of more and more researchers and engineers $[1,2,3]$.

Springback is a very common sheet forming defect. The springback amount influences indirectly the forming precision of workpiece. Springback of small curvature workpiece in the stretch forming and stamp forming is larger, the author consider using high-pressure water jet incremental forming instead of the stretch forming and the stamp forming. The author simulated the forming process of small curvature workpiece stamp forming and high-pressure water jet increment forming by software ABAQUS simulation, compared springback amount of the two kinds of forming, and analyzed the relationship between water jet pressure, interlayer distance and nozzle feed speed and the springback amount of small curvature workpiece in high-pressure water jet forming.

\section{Springback Comparison with High-pressure Water Jet Forming and Stamp Forming}

Workpiece material select $0.6 \mathrm{~mm} 2 \mathrm{~A} 12-\mathrm{O}$ state of aluminium plate used generally in aircraft skin, material parameters includes density, elastic modulus, etc. As shown in Table 1.

Table 1 Material performance parameters

\begin{tabular}{|c|c|c|c|c|c|}
\hline $\begin{array}{c}\text { Density } \\
/ \mathrm{kg} / \mathrm{m}^{3}\end{array}$ & $\begin{array}{c}\text { Roisson' } \\
\text { ration }\end{array}$ & $\begin{array}{c}\text { Elastic } \\
\text { modulus/MPa }\end{array}$ & $\begin{array}{c}\text { Strain hardening } \\
\text { exponent }\end{array}$ & $\begin{array}{c}\text { Yield } \\
\text { stress/MPa }\end{array}$ & $\begin{array}{c}\text { Harding } \\
\text { coefficient/MPa }\end{array}$ \\
\hline 2780 & 0.3 & $7.0 \times 104$ & 0.2236 & 82 & 312 \\
\hline
\end{tabular}

This parper studies mainly springback of the curvature of the scope for: $0.001 \sim 0.01$.Selected the size of curvature of the workpiece: 1/350, 1/300, 1/250, 1/200, 1/150.

Springback Analysis of Workpiece High-pressure Water Jet Forming. The principle of high-pressure water jet forming use the thought of "layered manufacturing", which forming part will 
be discretized into a series of two-dimensional section layer according to its height direction, using a bit of pressure water column hit the workpiece on two-dimensional layer section along a certain path, which make the workpiece plastic deformation form the final shape parts [1]. Principle diagram and cutting path are shown in Fig 1.
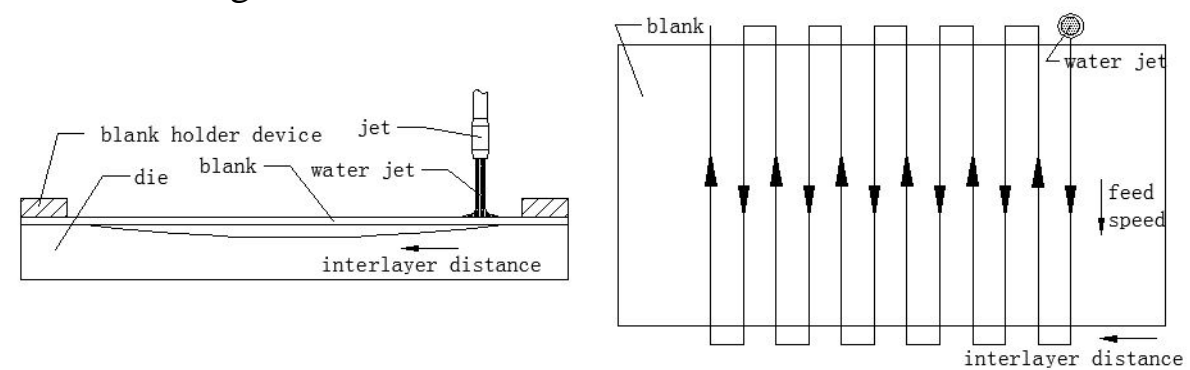

Fig. 1 The principle and cutting path chart of high-pressure water jet workpiece forming

Reasonable finite element model will determine the accuracy of the calculation result. Highpressure water jet forming technology belongs to a new method with sheet metal forming. Therefore, the study for the process of high-pressure water jet forming is less, the common model of water jet has two kinds: one kind use a rubber ball, another use a small round plate including the water jet pressure. The second model can better simulate impacting area of the water jet, therefore, this paper uses the model of the small round plate. The diameter of small round plate is $2 \mathrm{~mm}$. As shown in Fig 2 .

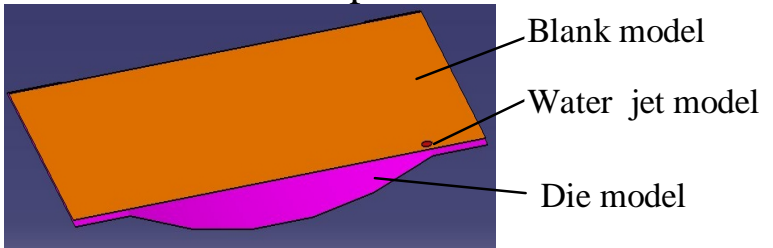

Fig. 2 The finite element calculation model of water jet forming

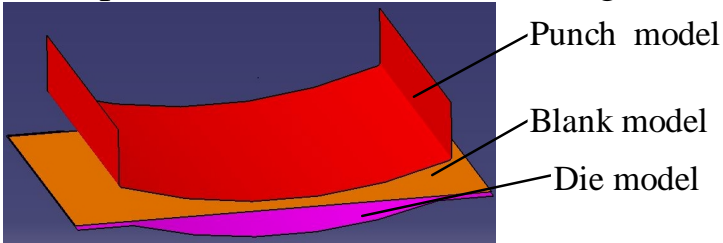

Fig. 3 The finite element calculation model of stamp forming

Springback Analysis of Worpiece Stamp Forming. The small curvature workpiece of aircraft have a lot, many of which belong to stamping parts, the analysis of springback to which has important reference significance in the stamp forming [4]. The springback simulation technology for stamp forming has been very mature now, the paper don't describe in detail. The finite element calculation model is shown Fig. 3.

The Springback Comparison. The resilience value under the two forming modes can be concluded to the high-pressure water jet forming and stamp forming by the springback simulation analysis. Resilience value can show by the vertical displacement of sheet metal forming. In order to more intuitive response springback is how to effect on the precision of parts forming, this paper compare the effect of springback by compare the resilient rate in the two forming.

Resilient rate calculation results as shown in Table 2.

Table 2 Resilient rate

\begin{tabular}{|c|c|c|c|c|c|}
\hline Curvature & $1 / 350$ & $1 / 300$ & $1 / 250$ & $1 / 200$ & $1 / 150$ \\
\hline plastic deformation/mm & 1.074 & 1.272 & 1.510 & 1.908 & 2.551 \\
\hline resilience value(stamp forming)/mm & 1.056 & 1.104 & 1.325 & 1.365 & 1.75 \\
\hline resilience rate(stamp forming)/\% & 98.3 & 86.8 & 87.7 & 71.5 & 68.6 \\
\hline resilience value(high-pressure water jet forming)/mm & 0.178 & 0.154 & 0.167 & 0.196 & 0.099 \\
\hline resilience rate(high-pressure water jet forming)/\% & 16.6 & 12.1 & 11.1 & 10.3 & 4.0 \\
\hline
\end{tabular}

It can be concluded to compare resilience rate under the different curvature through on the face that resilient rate that small curvature workpiece use high-pressure water jet forming is far less than the stamp forming, and improve the workpiece's precision. 


\section{The Analysis of Springback during High-pressure Water Jet Forming for Small Curvature Workpiece}

In the process of workpiece using high-pressure water jet forming, the forming mainly is affected by water jet pressure, interlayer distance, and feed speed of the jet, etc. Therefore, therefore, the springback and the selection of these parameters in high-pressure water jet forming have a great relationship. This paper analysize the springback of the workpiece for detailed to curvature for $1 / 350$ and $1 / 300$.

\section{Factor Analysis of the Springback in High-pressure Water Jet Forming}

Water Jet Pressure Effect on the Springback. The water jet pressure is the most important parameter to forming height and precision of high-pressure water jet forming, and forming height is linear relationship [2]. Therefore, the study of the springback for the small curvature workpiece using high pressure water jet forming must study the effect of water jet pressure on the springback. The simulation analysis of the effect on between the springback and water jet pressure is shown in Fig 4.

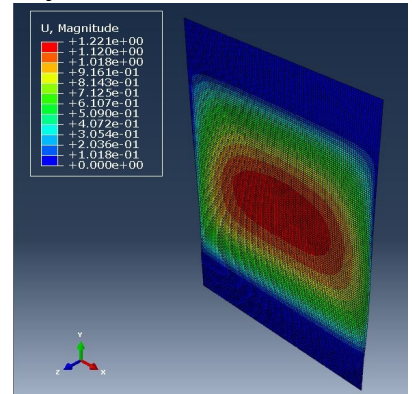

$40 \mathrm{MPa}$

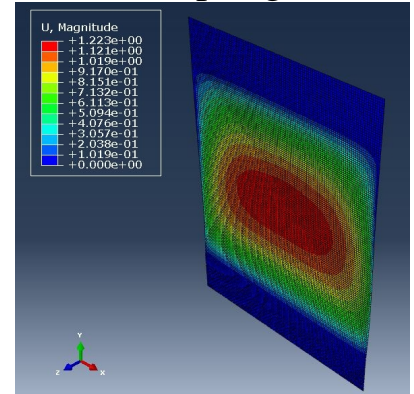

$50 \mathrm{MPa}$

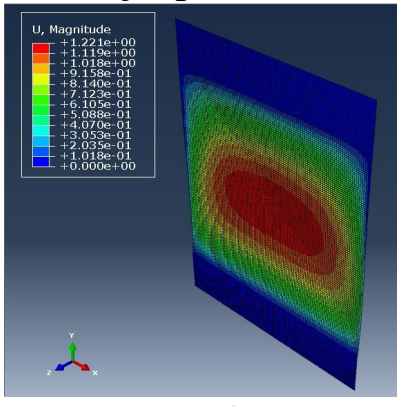

$60 \mathrm{MPa}$

Curvature $=1 / 350$, feed speed $=600 \mathrm{~mm} / \mathrm{min}$, interlayer distance $=2 \mathrm{~mm}$

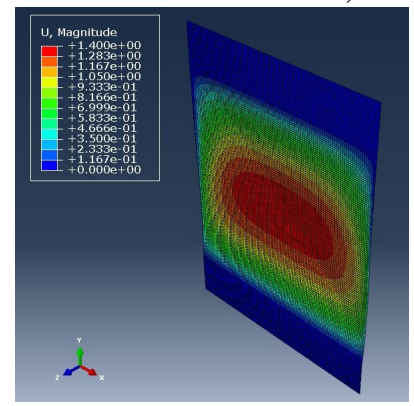

$40 \mathrm{MPa}$

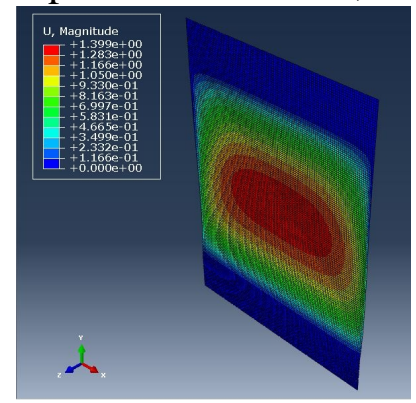

$50 \mathrm{MPa}$

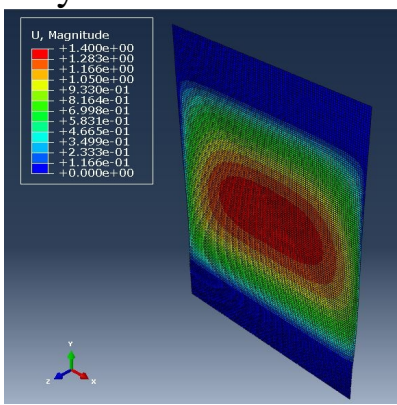

$60 \mathrm{MPa}$

Curvature $=1 / 300$, feed speed $=600 \mathrm{~mm} / \mathrm{min}$, interlayer distance $=2 \mathrm{~mm}$

Fig. 4 Pressure effect on the springback

Interlayer Distance Effect on the Springback. High-pressure water jet forming accuracy related to the interlayer distance: the smaller interlayer distance is, the better surface quality is, the higher shape accuracy is [2]. As a result, the analysis to springback in high-pressure water jet forming need to consider the effect of interlayer distance on the springback. The simulation analysis of the effect on between the springback and interlayer distance is shown in Fig. 5.

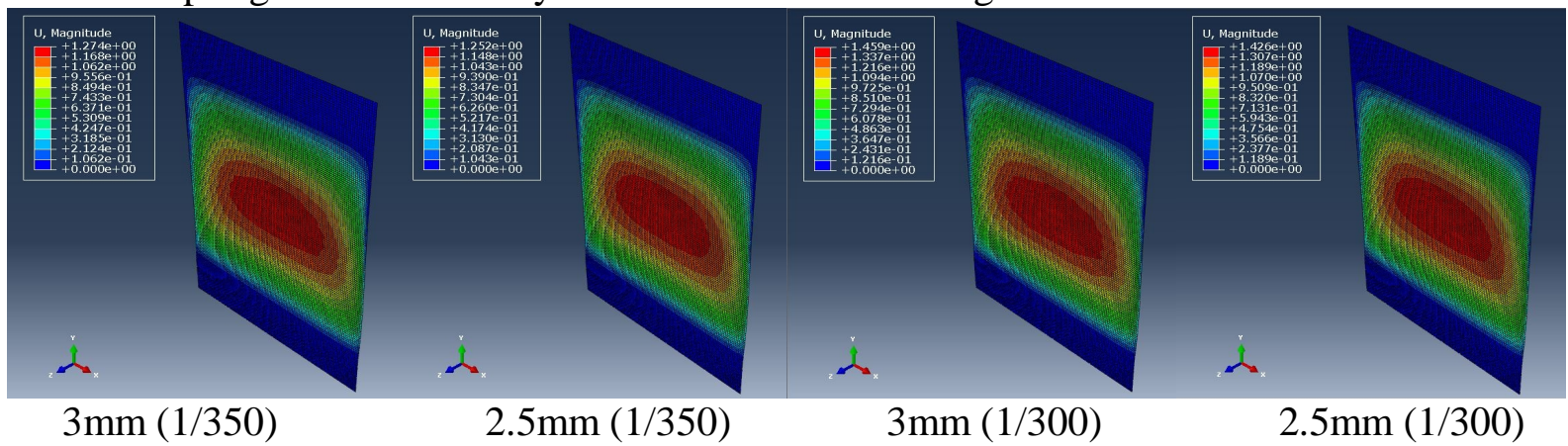

Fig. 5 Interlayer distance effect on the $\operatorname{springback}($ feed speed $=600 \mathrm{~mm} / \mathrm{min}$, pressure $=50 \mathrm{MPa})$

Feed Speed Effect on the Springback. The influence of feed speed to surface quality of the parts is not very big, which relate to efficiency [2]. Feed speed is also involved main process parameter in 
the high-pressure water jet forming, which may also affect the springback. The simulation analysis of the effect on between the springback and feed speed is shown in Fig. 6.

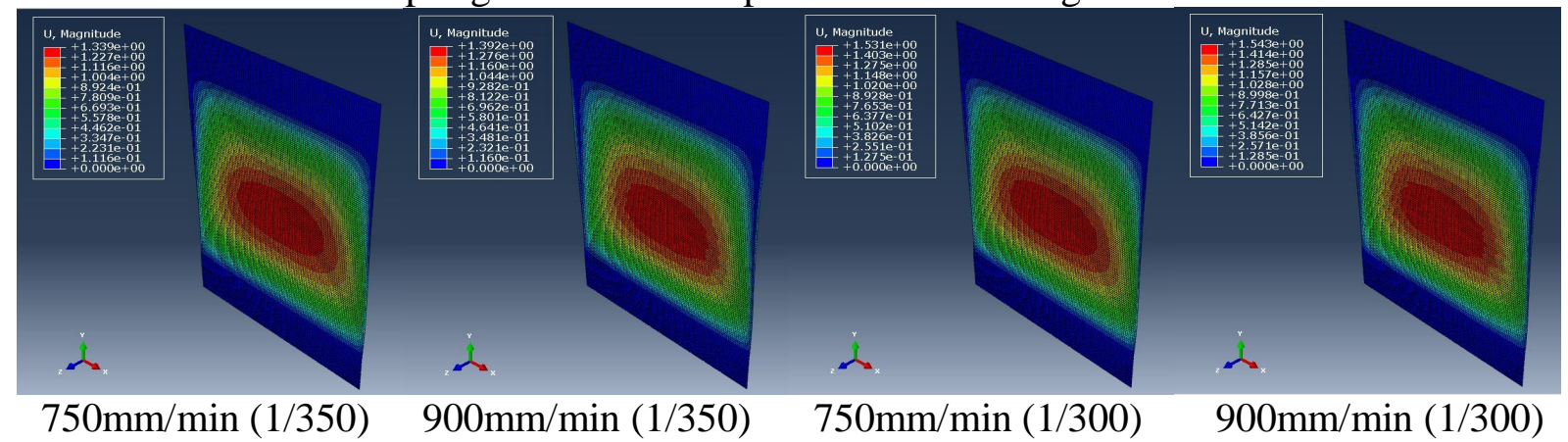

Fig. 6 Feed speed effect on the springback (interlayer distance $=2 \mathrm{~mm}$, pressure $=50 \mathrm{MPa}$ )

The Discussion of Results. It can be concluded by the springback simulation to high-pressure water jet forming that water jet pressure has no effect on the springback, as shown in Fig. 7(interlayer distance $=2 \mathrm{~mm}$, feed speed $=600 \mathrm{~mm} / \mathrm{min}$ ); interlayer distance and the springback have a linear relation, as shown in Fig. 8 (pressure $=50 \mathrm{MPa}$, feed speed $=600 \mathrm{~mm} / \mathrm{min}$ ); when water jet pressure and interlayer distance are certain conditions, the springback as the feed rate increases until the feed speed reaches $750 \mathrm{~mm} / \mathrm{min}$, after the springback amount can't change basically, as shown in Fig. 9 ( pressure $=50 \mathrm{MPa}$, interlayer distance $=2 \mathrm{~mm}$ ).

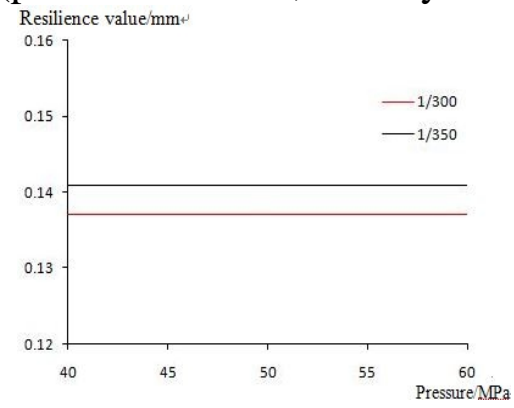

Fig. 7 Relation diagram of pressure and springback

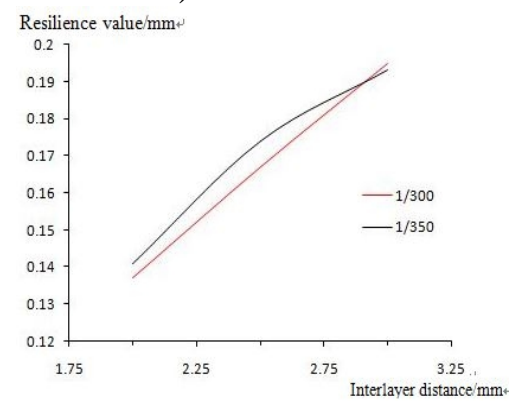

Fig. 8 Relation diagram of interlayer distance and springback

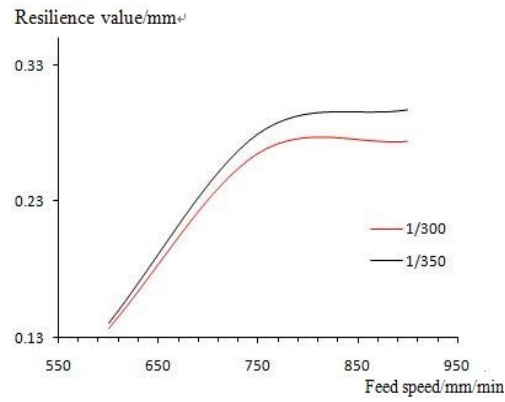

Fig. 9 Relation diagram of feed speed and springback

\section{Conclusion}

1. The springback during high-pressure water jet forming for small curvature workpiece is smaller than stamp forming. Therefore, a small curvature sheet metal use high pressure water jet that can improve better the forming precision of the small curvature workpiece.

2. The water jet pressure during high-pressure water jet forming for small curvature workpiece has no effect on the springback.

3. During high-pressure water jet forming for the small curvature workpiece, the greater interlayer distance is, the greater the springback is.

4. The springback during high-pressure water jet forming for the small curvature workpiece as the feed rate increases until the feed speed reaches $750 \mathrm{~mm} / \mathrm{min}$, after the springback amount can't change basically.

\section{References}

[1] Cheng Zhaohui, Research on the Technology High-pressure Water Jet Incremental Forming, Master Degree Thesis, Jilin University, 2008.5.

[2] Junlei Xiao, Research on Reasonable Parameters of High-pressure Water Jet Sheet Metal Forming Process, Master Degree Thesis, Shenyang Aerospace University, 2012.1.

[3] Zhang Ling-yun, Zhang Fei, Development of Water Jet Incremental Sheet Metal Forming, Foundry Technology, 2010.5:649-651. 
[4] Xu Bing-kun, SHI Fa-zhong, Numerical Simulation of Springback in Sheet Metal Forming, Journal of Beijing University of Aeronautics and Astronautics, 2001 (4) : 194-196. 